\title{
"Esa vacua y petulante invención de la vulgaridad": Nueva York, estética del anuncio, y sociedad de consumo en la obra de Joaquín Torres-García (1920-21)

\author{
"Vulgarity's Vain and Smug Invention": New York, the Aesthetics \\ of Advertising, and Consumer Society in the Work of Joaquín
} Torres-García (1920-21)
}

\author{
Brais D. Outes-León \\ Queens College, CUNY
}

En su ensayo New York (1920-30), el pintor uruguayo Joaquín Torres-García analiza la estrecha relación entre la industria publicitaria y la vulgaridad espiritual de la sociedad de consumo. A pesar de su entusiasmo por la estética visual del anuncio, Torres-García denuncia cómo la lógica del materialismo que opera en el seno de la publicidad produce una vulgarización de las sociedades capitalistas. La industria publicitaria aspira al disciplinamiento de las subjetividades y la transformación de los sujetos en una masa anónima por medio de estrategias discursivas de manipulación psicológica que banalizan la afectividad humana a partir de su mercantilización.

Palabras clave: Publicidad, Nueva York, Torres-García.

In his essay New York (1920-30), the Uruguayan painter Joaquín Torres-García analyzes the tight connection between advertising industry and the spiritual vulgarity of consumer society. Despite his enthusiasm for the visual aesthetics of advertisement, Torres-García denounces how the materialist logic that operates at the heart of advertising results in a vulgarization of capitalist societies. The advertising industry aspires to disciplining subjectivities and transforming individuals into an anonymous mass. This is achieved through discursive strategies based on psychological manipulation that banalize human affectivity by transforming it into a commodity.

Keywords: Advertising, New York, Torres-García. 
"El anuncio comercial nos causa una emoción de dimensiones infinitamente superiores a la que nos producen los quilómetros de pintura cualitativa que infestan nuestros salones".

Salvador Dalí, "Guía sinóptica: El anuncio comercial" 164. ${ }^{1}$

Pocos discursos de la cultura de masas a lo largo del siglo XX han sufrido mayor nivel de descrédito y desdén que la práctica cultural del anuncio publicitario. Despreciada con frecuencia por intelectuales y artistas como un fenómeno vulgar fiado a los intereses económicos del anunciante como única razón de ser, la publicidad se erige, sin embargo, para las vanguardias históricas de la década de 1920 en un sinónimo de una nueva estética de la modernidad urbana. Con su irreverente falta de pretenciosidad, su vínculo con la cultura popular, su mercantilismo sin complejos, y su uso de nuevos discursos visuales y tipográficos en novedosas configuraciones multimediales las vanguardias históricas ven en la publicidad un discurso cultural alternativo que -al igual que otras formas de producción cultural de masas como el jazz, el cine, la radio, o los musicales- se opone a las convenciones tradicionales del arte institucionalizado de principios de siglo. Esta atracción hacia la publicidad se plasma con elegancia matemática en el dictum del poeta francés Blaise Cendrars. Para gran parte de las vanguardias históricas, "Publicidad = Poesía" (207).

Este interés por la publicidad como fenómeno cultural la convierte en un tema y fuente de inspiración recurrente para escritores vanguardistas latinoamericanos de estéticas tan diversas como los estridentistas mexicanos Manuel Maples Arce y Germán List Arzubide, el chileno Pablo de Rokha, o los peruanos Nicanor de la Fuente y Rafael Méndez Dorich. ${ }^{2}$ En el contexto de las vanguardias latinoamericanas, sin embargo, destaca de forma notoria el ensayo New York (1920-30) del pintor y escritor uruguayo Joaquín TorresGarcía. Escrito entre 1920 y 1930 en un proceso de constantes reescrituras y fallidas tentativas de publicación que solo fructificaron póstumamente en 2007, este texto de difícil clasificación genérica presenta las reflexiones y tribulaciones en primera persona de un pintor europeo anónimo recién llegado a la ciudad. ${ }^{3}$ Vagamente basado en la estancia del pintor en Nueva

\footnotetext{
1 Para facilitar la fluidez de la lectura, he traducido al español los textos originalmente escritos en otras lenguas. La bibliografía adjunta mantiene, sin embargo, las referencias a los textos originales.

2 Aunque analizar el impacto de la publicidad en la poesía latinoamericana de esta época excede los objetivos de este ensayo, caben destacar las referencias a la publicidad en poemas como "Prisma" (Los andamios interiores, 1922) de Manuel Maples Arce, y "Paleta-chicles" (Esquina, 1923) y "La novia extra. III" (El viajero en el vértice, 1927) de Germán List Arzubide; así como el empleo de collages de textos publicitarios es empleado, además, por Nicanor de la Fuente en su poema "Contraseña" (Amauta 15, mayo-junio 1928), por Rafael Méndez Dorich en "Elegía de Jack Mike Black, Jack el virtuoso del saxo" (Dibujos animados, 1936), y por Pablo de Rokha en su poema en prosa "Las tiendas" (Los Gemidos, 1922).

3 La historia del texto es compleja. Varias secciones del ensayo fueron publicadas como artículos sueltos en la revista catalana La Publicidad en 1920 ("Apunts sobre Nova York", "New York", y "New York, los artistas"), pero el texto íntegro solo fue publicado en 2007 gracias al trabajo archivístico de Juan Fló. Se conservan, además, tres versiones del texto: un manuscrito ilustrado y fechado en 1921; una copia dactilográfica con algunas modifi-
} 
York (1920-21), donde trabajó como dibujante para la pujante industria publicitaria, New York constituye un ejemplo paradigmático de la importante labor como escritor y divulgador que Torres-García compaginó con su obra pictórica. A medio camino entre el ensayo, el diario autobiográfico, y la fértil tradición latinoamericana de crónicas neoyorquinas inaugurada por José Martí en la década de 1880, en New York Torres-García desarrolla una radiografía de la modernidad norteamericana en la que lidia con temas tan variados como el dinamismo y actividad económica de la gran urbe, la tecnologización de la vida moderna, la alienación de un pintor extranjero en una nueva cultura, o la higiene y dinámicas de género en la sociedad norteamericana. Entre los diferentes temas tratados en el ensayo el fenómeno de la publicidad ocupa una posición central.

Las constantes reflexiones desarrolladas por Torres-García sobre las implicaciones visuales, económicas, éticas, e incluso psicológicas de la publicidad para una comprensión de la modernidad contemporánea, hacen de New York una de las contribuciones ensayísticas más sofisticadas sobre el tema escrita por un artista vanguardista. ${ }^{4}$ Centrándome en un análisis pormenorizado de New York, en este trabajo propongo mostrar cómo, en contraste con el entusiasmo desbordante de la mayoría de artistas vanguardistas por las nuevas estéticas del anuncio, Torres-García desarrolla un análisis marcadamente negativo de la industria publicitaria. A pesar del interés de Torres-García por el impacto visual del anuncio en el paisaje urbano, la publicidad es denunciada en las páginas de New York como la expresión más llamativa de la "vacua y petulante invención de la vulgaridad" que caracteriza a la sociedad norteamericana (128). Como veremos a continuación, para Torres-García, la vulgaridad publicitaria estriba en su perniciosa capacidad para estandarizar y empobrecer espiritualmente al individuo por medio de prácticas discursivas deshumanizantes que banalizan hasta la caricatura los más nobles sentimientos e ideales humanos. La tensión que se percibe en New York entre la atracción hacia la visualidad publicitaria y el desprecio por su supuesta vulgaridad espiritual muestra de forma inequívoca la compleja y, en ocasiones contradictoria, actitud de las vanguardias históricas hacia la vibrante cultura de masas de la década de 1920.

\section{Bajo el hechizo de "la ciudad del afiche"}

El 16 de junio de 1920, Torres-García desembarca en los muelles de Manhattan a bordo del transatlántico Leopoldina en compañía de su numerosa familia y con la idea de probar fortuna en la gran metrópolis norteamericana.

caciones de 1921; y un manuscrito fechado en 1930 con numerosas modificaciones, un prólogo y cuatro secciones adicionales concebido como la base para una edición francesa que nunca llegó a realizarse (Fló "Introducción" 49).

4 Entre los ensayos vanguardistas que lidian en mayor o menor medida con el tema de la publicidad, cabe destacar "Crónicas y palabras sobre el arte: La pintura moderna" (1913) de Guillaume Apollinaire, "Publicidad = Poesía" (1931) de Blaise Cendrars, y "Guía sinóptica. El anuncio comercial. Publicidad. Propaganda" (1927) de Salvador Dalí, Lluís Montanyá y Sebastià Gasch. Mención especial merecen los escritos futuristas sobre publicidad, entre los que destacan el manifiesto Poesía publicitaria (1933) de Giovanni Gerbino y "El futurismo y el arte publicitario" (1931) de Fortunato Depero. 
Aunque el pintor contaba con importantes contactos dentro de la escena del arte como Marcel Duchamp, Joseph Stella y Max Weber, y llegó a participar en exposiciones en el Whitney Studio Club y en la Academia de Bellas Artes de Filadelfia, su estancia neoyorquina estuvo marcada por agudas estrecheces económicas y numerosos sinsabores profesionales. Relativamente conocido en los medios artísticos catalanes, pero sin gozar todavía del estatus de gran figura internacional del arte, la precariedad económica obligará a Torres-García a ganarse la vida trabajando como pintor de decorados en Broadway y dibujante para la industria publicitaria. ${ }^{5}$ Aunque el pintor ya había gozado de experiencias profesionales al comienzo de su carrera en el ámbito publicitario en la Barcelona de Fin de Siglo, su experiencia profesional en la industria publicitaria neoyorquina tendrá un enorme impacto en la producción artística de Torres-García durante este periodo -como pone de manifiesto la centralidad otorgada en New York a la avasallante proliferación de anuncios que caracteriza el paisaje urbano de la ciudad-. ${ }^{6}$ En la descripción introductoria de Manhattan que da comienzo al ensayo, Torres-García muestra su fascinación por el efecto que producen los nombres de marcas, eslóganes, precios, y logotipos publicitarios que atestan las calles. En este primer párrafo del ensayo, el pintor enfatiza la intensidad y dinamismo de la gran ciudad, capaz de saturar la mente del viandante con una profusión insólita de información visual:

Primera impresión [que seguramente tendré que rectificar -Impresión] plástica -interesantísima para un artista moderno - mil formas nuevas en movimiento que llega al paroxismo - superficies enormes con mil agujeros rectangulares - escaleras bajando en zigzag desde lo alto - planos, en movimiento vertiginoso - ascensores, elevados, subterráneos: - números $56,56,56,56$, pasando rápidamente en los postes - 56 - estación - parada brusca - mil personas en opuesta dirección, jadeantes - luces multicolores - ruido atronador. - El square - árboles - tranvías - sombreros de paja - colores al sol - bazares, autos, camiones - casas rojas, amarillas, grises. - Anuncios - fijos, móviles, luminosos, acústicos, bajando, subiendo, vibrando siempre, sin dejar reposo a la sensibilidad ... New York: una gigante, inimaginable casa de comercio. - En el periódico - en los espectáculos - en el arte - en los libros - en el taller del arquitecto - en la universidad - en el museo - en el thé - en las anchas descomunales fachadas de las casas, invadidas por el anuncio. (59, subrayado nuestro)

\footnotetext{
5 Sobre la estancia de Torres-García en Nueva York, véanse su escrito autobiográfico Historia de mi vida (1939) (187-221); y los artículos de Cecilia de Torres y Juan Fló que acompañan el catálogo de exposiciones Trazos de New York (2011) y la introducción al texto New York (Fló "Introducción").

6 Ya en 1898, durante sus años formativos en Barcelona, Torres-García diseñó numerosos carteles publicitarios para revistas como El Gato Negro -fuertemente influido por ToulouseLautrec y otros exponentes del cartel artístico de Fin de Siglo-. Sobre este periodo de la carrera del pintor uruguayo, véase Jardí 14-16, 18.
} 
Mediante la elipsis verbal en las enumeraciones y la eliminación de la oración como unidad de significado sintáctica en pos de fragmentos separados por guiones, Torres-García produce un texto profundamente fragmentario en el que se intenta reproducir verbalmente el paroxismo de las "mil formas nuevas en movimiento". Más allá del énfasis en el movimiento y la saturación de estímulos visuales, esta primera impresión plástica de la ciudad está completamente mediatizada por el estímulo intoxicante de la publicidad. La variedad de formas, colores y tipologías publicitarias que invaden el paisaje urbano satura la sensibilidad del espectador. Ante esta realidad visual, Torres-García describe Nueva York como "la ciudad del color -la ciudad del afiche- la ciudad de las mil formas insospechadas" (64).

La saturación de anuncios que documenta Torres-García en las páginas iniciales de su ensayo demuestra su interés por la publicidad, no como una práctica artística vinculada con las artes decorativas (como era el caso del póster artístico finisecular), sino como un fenómeno discursivo masivo fuertemente vinculado con las sinergias económicas de la modernidad capitalista. La colonización -ad nauseam- del paisaje urbano por la publicidad, está estrechamente vinculada con el auge histórico de la publicidad como fenómeno cultural entre 1880 y 1920 . Como consecuencia del aumento del consumo de productos manufacturados que se produce tras la Segunda Revolución Industrial, la publicidad se erige en lo que Raymond Williams bautiza como "el arte oficial de la sociedad capitalista moderna" (184) -el principal vehículo de difusión y promoción de las nuevas formas de consumo. ${ }^{7}$ En este contexto de grandes cambios económicos y culturales en el que se desarrolla la sociedad de consumo como la conocemos hoy en día, Nueva York -centro económico de los EE.UU. y mayor metrópolis del planeta- se erige en la Meca indiscutible de la industria publicitaria. La ciudad que describe Torres-García es un espacio urbano hipercodificado, dominado por los discursos culturales y convertido en lo que Jean Baudrillard, al reflexionar sobre las metrópolis de la posmodernidad, llama "una fábrica de signos, de medios, de código" (120). Para Torres-García, Nueva York es un paisaje invadido hasta el tuétano por el discurso publicitario:

El anuncio invade la pared - en las anchas fachadas en lo alto de las altas casas - en cualquier muro - en cualquier superficie alta o baja - en mil formas - en mil dimensiones. - Invade el periódico - sin dejar espacio para otras cosas. Invade las revistas - sin que quede lugar para nada más. - Ocupa hasta el más pequeño espacio aprovechable en los tranvías elevados y subterráneos - en el ómnibus - en los ferry-boats. (81)

Aquejada de una suerte de horror vacui, Nueva York abraza una estética del estímulo visual en la que todo espacio urbano es puesto al servicio de la práctica publicitaria. En este periodo que Theodor Adorno y Max Horkheimer llaman "la edad de la publicidad universal" (156), la industria publicitaria

7 Para una historia de la publicidad durante el periodo 1880-1930, véase Checa Godoy 31-70 y Eguizábal 121-231. 
sobrepasa, según el pintor, en importancia económica a la fabricación industrial de los productos anunciados. "La fiesta luminosa del Broadway" que cada noche bombardea al peatón con "el grito, en competencia, de cada anunciante" es la manifestación visual de un nuevo capitalismo en el cual la promoción le hace sombra a la producción. "Un billón de dollars - cada año - en anuncios", confirma Torres-García: "tres cuartas partes del capital para el anuncio, una parte para la industria" (70).

Como máxima expresión de la nueva sociedad de consumo que se gesta en las calles de Nueva York durante la década de 1920, el espectáculo visual de la publicidad adquiere una importancia mayúscula, no solo en New York, sino también en la obra pictórica de Torres-García de este periodo. Como tantos otros artistas vanguardistas, Torres-García aspira a desarrollar una nueva visualidad vanguardista capaz de dar expresión a la realidad de la gran ciudad mediante la incorporación de nuevos fenómenos culturales como la publicidad. La centralidad otorgada al anuncio en su obra pictórica neoyorquina constituye un claro ejemplo de la inversión de valores artísticos que constituye, según Torres-García, la razón de ser del proyecto vanguardista. "Lo que se juzgaba antiestético" -no apto para la representación artística en un cuadro serio según los criterios tradicionales del arte occidental-, "ahora es lo estético" para las vanguardias históricas (107). ${ }^{8}$ Esta reivindicación del valor estético del anuncio como motivo artístico se plasma en Álbum de acuarelas de New York (1920) -un cuaderno que incorpora bocetos de campañas publicitarias, collages con recortes de anuncios, y escenas de las calles de la gran urbe norteamericana, elaborados por Torres-García durante su estancia en EE.UU. En estos bocetos de anuncios -como este de la marca de cigarrillos Camel (imagen 1)-, Torres-García estudia las técnicas y composiciones visuales de las campañas publicitarias de diferentes productos de consumo -desde relojes y cerillas, a vinagre de sidra y boletos de viaje-. Es, sin embargo, en sus cuadros sobre el paisaje urbano de Nueva York donde la publicidad se erige en el motivo temático central de la nueva cultura urbana.

En Escena urbana de Nueva York (1920) (imagen 2) -un cuadro paradigmático de la experimentación formal de este periodo-, Torres-García explora las posibilidades visuales de la textualidad publicitaria hasta el extremo. De la misma manera en que el párrafo introductorio de New York reproduce por medio de la elipsis verbal y las interminables enumeraciones la intensidad sensorial de la experiencia urbana, Torres-García satura la superficie del cuadro con una avasalladora proliferación de imágenes y planos superpuestos que cubren la totalidad de la superficie del lienzo. En el caos de líneas rotas, de planos y formas, y de multitud de colores que componen esta escena, sobresalen las letras y números de las inscripciones publicitarias que pueblan el paisaje urbano. Como las experimentaciones de Filippo Tommaso Marinetti con nuevas tipografías literarias que se plasman en sus parole in libertà, los textos publicitarios representados por Torres-García en este cuadro rompen con los rígidos parámetros de la tipografía tradicional,

8 Como afirma rotundamente el pintor en el ensayo, solo el arte moderno que él mismo practica está capacitado para "fijar esta incomparable visión de los business" de la gran ciudad sobre un lienzo (91). 
creando un nuevo régimen de la visualidad pictórica en el que la palabra publicitaria, injertada en el caótico medio urbano de Nueva York, adquiere una nueva presencia material en la propia superficie del cuadro. ${ }^{9}$ Además de las palabras claramente identificables en esta escena urbana ("AMERICA", "ICE", "SODA", "MENS", "AFTERGLOW", "SEPTEM 15 Wednesday", etc.), las numerosas palabras e inscripciones no legibles o fragmentarias que se entremezclan con los vehículos en movimiento y los edificios - "R", "D", "Da", "PA", "EXP", "Chad", "18", entre otras muchas- reproducen en el lienzo la imposibilidad de una visión totalizante en el medio del caos visual de la gran urbe. A partir esta fragmentación textual y de su cuestionamiento de las leyes tradicionales de la perspectiva y la composición paisajística, Escena urbana se convierte en un espacio de reflexión estético en el que el observador es confrontado con el desafío epistemológico de interpretar -y literalmente leer- la fragmentación y caos sensorial que produce la ciudad simbolizados por las letras y números que pululan por el lienzo. ${ }^{10}$

La reivindicación del valor visual de la publicidad como uno de los motivos paradigmáticos del paisaje urbano de la modernidad capitalista que se desarrolla en New York y en Escena urbana parece, en primera instancia, alinearse con la celebración triunfal de la publicidad que caracteriza el pensamiento de artistas vanguardistas como Fortunato Depero, Blaise Cendrars, y Salvador Dalí. Sin embargo, como analizaremos a continuación, en New York este reconocimiento del enorme impacto de los anuncios en el paisaje urbano de la modernidad, no impide a Torres-García formular una denuncia sistemática de la publicidad como una industria discursiva de masas que produce con sus prácticas una gradual deshumanización y vulgarización del individuo en la sociedad capitalista.

\section{La vulgaridad de la sonrisa publicitaria}

En contraste con su atracción hacia el impacto visual del anuncio en el paisaje urbano, en New York la voz narrativa denuncia sistemáticamente a la industria publicitaria como la expresión más extrema del mercantilismo y la falta de valores que caracteriza la modernidad capitalista. Empleando el binomio desarrollado por Umberto Eco para designar las dos actitudes contrapuestas de los intelectuales frente a la cultura popular en el siglo XX, en craso contraste con su incorporación "integrada" de la textualidad publicitaria a su visualidad vanguardista, Torres-García da rienda suelta en otras secciones de su ensayo a una actitud "apocalíptica" de rechazo hacia la insufrible vulgaridad ética y espiritual de la publicidad. A partir de esta dialéctica sin síntesis entre la atracción visual y el desprecio ético, Torres-García defiende alternadamente dos posturas divergentes sobre la publicidad y la sociedad

\footnotetext{
9 Sobre el enorme influjo de la tipografía publicitaria en las vanguardias históricas, véase Drucker 91-104.

10 Además, frente a la tela, el observador ha de decodificar las nuevas estrategias de representación pictórica basadas en la fragmentación, la superposición de planos, el uso del collage, y la composición esquemática que desintegra palabras y objetos, de la misma manera en que intenta dar sentido al conjunto de letras y palabras que dominan el panorama paisajístico de Nueva York.
} 
norteamericana. Lejos de ser una muestra de falta de rigor discursivo, esta dialéctica irresuelta en el seno del ensayo muestra la sofisticación intelectual de un Torres-García dispuesto a explorar las tensiones y contradicciones de su pensamiento frente a la publicidad mediante un efectivo juego de contrapunteo discursivo. ${ }^{11}$

Para Torres-García, la vulgaridad de la publicidad no deriva de las características plásticas del discurso publicitario, sino de su función problemática dentro de la emergente sociedad de consumo de comienzos del siglo XX. En un tono que profundiza y expande los motivos y el vocabulario arielistas desarrollados por el ensayista uruguayo José Enrique Rodó, en New York Torres-García denuncia la naturaleza grotescamente materialista de una sociedad dominada única y exclusivamente por criterios mercantiles y utilitaristas. ${ }^{12}$ Como encarnación discursiva por antonomasia de la modernidad capitalista, los anuncios se erigen en el epicentro de una nueva cultura de lo vulgar en el que los valores éticos y espirituales brillan por su ausencia, sustituidos por una lógica económica que reduce todos los aspectos de la vida humana a un mero análisis de costes de producción, precio, y beneficio.

La vulgaridad de una sociedad norteamericana entregada al consumo descontrolado se plasma en una constante crítica a Nueva York como una Babilonia contemporánea borracha de riquezas materiales que, sin embargo, carece de toda "huella del espíritu" (95). Descrita entusiastamente en la primera sección del ensayo como "mi ciudad - la ciudad más Ciudad", Nueva York es denunciada ahora como un páramo materialista en el que el idealismo brilla por su ausencia (61). ${ }^{13}$ En una civilización en la que, según Torres-García, "la idea no existe", el goce espiritual es reemplazado por "el placer material: - baseball - regatas - juegos luminosos en el teatro - sonidos musicales mecánicos - picnics - ice-cream - sports - danza - ingenios mecánicos de pasatiempo - cinematógrafo... y el ideal común: dollars!" (7071). Inundada por todo tipo de baratijas y carente de verdadera alma, la urbe se convierte en un espacio de vulgar mercantilización, en el que la voz narrativa ya no se reconoce. Cegada por su propia abundancia material, la gran metrópolis pierde de vista cualquier ideal, convirtiéndose en "la ciudad del chewing-gum, la ciudad de los candy perfumados al linoleum, la ciudad del barniz y la goma laca, la ciudad del camelote, [que] brinda toda esa suerte

11 En un ejercicio de esquizofrenia discursiva, la voz narrativa se desdobla para dar expresión a opiniones contrapuestas, llegando a entablar diálogos interiores consigo misma en los que emplea la tercera persona para referirse a su "otro yo:" "El artista ha escuchado atentamente [la opinión de su otro yo] sin hacer la menor objeción. Después ha hablado de esta manera: no voy a refutar ni una sola de las razones que usted ha expuesto" (125). Esta tendencia a la fragmentación de sus sensibilidades e imposturas críticas en diferentes voces contrastivas, es una técnica literaria que Torres-García emplea en otros textos como Diàlegs (1915), El descubrimiento de sí mismo. Cartas a Julio, que tratan de cosas muy importantes para los artistas (1917) y La ciudad sin nombre (1941).

12 Torres-García admiraba profundamente el pensamiento de Rodó y llegó a contactarlo por carta durante la estancia de este último en Europa (ver Torres-García "Carta a José"). Sobre la visión arielista sobre los EE.UU., véase Rodó 35-51.

13 Fruto de esta insatisfacción, Nueva York llega a describírsenos como una prisión que aplasta al artista" e incluso como un infierno dantesco del cual el artista no consigue escapar $(73,85-89)$. 
de felicidades a la mediocridad (que obtiene buenos dollars sin sacrificio de ningún ideal) porque no le tiene" (82). La vacuidad de este consumismo se cimienta en la incansable labor de promoción desarrollada por una publicidad que deja de ser un mero aspecto pintoresco del paisaje urbano de la gran ciudad para erigirse en la esencia misma de la sociedad norteamericana:

"[la publicidad] es precisamente el orgullo de este país, lo que da tono y color a este país. Toda su mentalidad, todo su vivir moral y material está ahí [en la publicidad] - iba a decir toda su espiritualidad. - Y si no, dígame: ¿qué queda de este pueblo si se quita eso $y$, naturalmente el comercio y la industria que motivan ese grito del anunciante? iNada...! (139).

El remolino de imágenes publicitarias que había capturado la imaginación del pintor en un primer momento, se nos desvela como un espejismo incapaz de encubrir la ausencia de valores espirituales y estéticos. Para un TorresGarcía claramente "apocalíptico", el anuncio se convierte en el alfa y omega de la vida cultural de esta sociedad dominada por el consumo.

Lejos de ser un mero síntoma de la vulgaridad espiritual de la modernidad capitalista, la publicidad emerge en las páginas de New York como una práctica discursiva imprescindible para su correcto funcionamiento. A pesar de su aparente informalidad, la publicidad era ya en la década de los años 1910 y 1920 una industria altamente profesionalizada que incorporaba de forma sistemática sofisticadas técnicas de manipulación basadas en los últimos avances de la psicología behaviorista. "El anunciante", nos alerta Torres-García con conocimiento de causa, "aplica los conocimientos psicológicos para mejor vender tal o cual producto, y de esta aplicación saca gran provecho" (113). Empleando avanzadas técnicas de manipulación, la publicidad aspira no solo a vender un producto, sino a moldear el comportamiento, la apariencia, y en última instancia, los deseos y aspiraciones de los compradores mediante técnicas de manipulación psicológica. El objetivo último de la publicidad en las sociedades contemporáneas $-y$ su aspecto más problemático, según Torres-García- es la estandarización y uniformización de la psicología de los individuos. La ciudad hipertrofiada de publicidad descrita por Torres-García no es ya una simple "fábrica de signos", sino una siniestra fábrica de seres humanos anónimos, indistinguibles los unos de los otros, en los que cualquier atisbo de individualidad es reprimido por medio del lenguaje omnipresente del anuncio. En la sociedad industrializada descrita en las páginas de New York, la industria publicitaria convierte al individuo en un autómata carente de una subjetividad realmente propia. "Todo aquí es industrial", denuncia el pintor, "por eso (como aquí dicen) - todo tiene que estar dentro del estilo: hombres y cosas. Industrializado: hombres y cosas" (70). ${ }^{14}$

14 El motivo del individuo convertido en máquina es recurrente a lo largo de todo el ensayo. En los EE.UU., "el hombre es una máquina $-y$, todo cuanto toque- $y$ todo cuanto mire, producto de la industria" (78). Véase, además, 69. 
La sociedad que emerge de las prácticas publicitarias es una sociedad constituida por masas de individuos sin atributos -esculpidos eslogan a eslogan-. En las multitudes de la gran urbe, la voz narrativa solo atisba a distinguir monigotes cortados por un mismo patrón: "al mismo hombre - ocupado siempre en lo mismo - el teléfono pegado a la oreja - la pluma dispuesta a hacer sobre el papel - para anotar un guarismo - una marca - una fecha - el nombre de un objeto - jamás una idea. Y la misma mujer, siempre - y siempre frente al hombre en mangas de camisa" (73, cursivas nuestras). Las masas indiferenciadas esculpidas por el lenguaje de la publicidad en las que la individualidad desaparece constituyen el resultado de la invasión incontrolable del medio urbano por el anuncio. El resultado no es otro que la emergencia de una nueva cultura de masas que Torres-García asocia con una vulgarización en el sentido etimológico del término -una degeneración del sujeto en la masa informe del vulgo-. ${ }^{15}$

Siguiendo la tradicional denuncia modernista de la tiranía de la mediocridad y el número frente al talento en la sociedad norteamericana que Rodó define en el Ariel como la "nivelación mesocrática" (44), el pintor uruguayo se ve a sí mismo como una víctima de esta sociedad vulgarizada por las prácticas publicitarias que reprimen las sensibilidades verdaderamente artísticas. ${ }^{16}$ En un medio social represivo en el que las sensibilidades no normativas no tienen cabida y en la que todos los individuos han de vestir y actuar de forma estandarizada, Torres-García se siente incomprendido y profundamente alienado. Forzado a trabajar en la industria publicitaria para poder sobrevivir económicamente, Torres-García percibe su situación como una traición a su vocación artística. Dentro de la lógica de la estandarización que subyace a la sociedad norteamericana, no solo el consumidor es disciplinado, sino también el propio artista que es obligado por la necesidad a poner su talento artístico al servicio de los intereses y necesidades comerciales de la industria publicitaria. Como reconoce el pintor en una carta enviada a su amigo y confidente Rafael Barradas en 1920, en última instancia, trabajar para la industria publicitaria implica una sumisión artística:

Aparte de las firmas acreditadas en Europa: Sorolla, Zuloaga, Blasco Ibáñez y otros por el estilo, los demás

15 La importancia de la estandarización que subyace a la lógica publicitaria se plasma en la veneración reverencial que, según Torres-García, sienten los norteamericanos por el standard -un principio de organización según el cual todas las cosas y los individuos han de obedecer a las mismas tendencias, dimensiones, y principios: "el standard- en todo orden de cosas, que no permite que jamás nadie viole. Por esto, no permite tampoco que el extranjero conserve su carácter, ni sus costumbres, ni su personalidad - él quiere americanizarlo todo, absorberlo todo, en beneficio del progreso humano" (109). En una sociedad étnicamente diversa como la norteamericana que como afirma el pintor, no es "un pueblo, sino una organización", el estándar adquiere, además, una importancia política como elemento de unificación identitario (114).

16 La tiranía del número ya señalada por Alexis de Tocqueville al hablar de la democracia norteamericana, lleva a Rodó a denunciar en el Ariel que, como demuestra el caso de Edgar Allan Poe, "el arte verdadero solo ha podido existir en tal ambiente, a título de rebelión individual" (43). "La democracia", apostilla el ensayista uruguayo, "a la que no han sabido dar el regulador de una alta y educadora noción de las superioridades humanas, tendió siempre entre ellos a esa brutalidad abominable del número que menoscaba los mejores beneficios morales de la libertad" (46). 
hacen arte comercial. La industria necesita eso. Y lo pagan espléndidamente. Carteles, anuncios de diarios y revistas, etiquetas, etc. todo fotografías. Y si no trabaja [Ud.] en algo de eso, se muere de hambre ... ("Carta" 163, subrayado en el original).

En una sociedad dominada por masas de individuos vulgarizados carentes de verdadera subjetividad propia, no hay espacio creativo para sensibilidades estéticas no normativas y verdaderamente transgresoras. En este medio social represivo, los pintores vanguardistas viven en la miseria o se pliegan a las prosaicas necesidades de la promoción comercial. Como se dice a sí mismo un desencantado Torres-García, "vuelve a meter todos los cuadros en las cajas porque nada de todo eso sirve para sacar dinero - aquí no hay más que arte comercial" (New York 83). ${ }^{17}$

En su análisis de la lógica del disciplinamiento de las subjetividades que subyace a la industria publicitaria, Torres-García presta especial atención a la estandarización de los afectos. Según el pintor, la sociedad norteamericana está dominada por un imperativo de la felicidad que obliga a todo individuo a sonreír de forma grotescamente compulsiva. La felicidad en los EE.UU. no es un derecho, sino un deber que los anuncios se encargan de imponer discursivamente: "Keep smiling (manténgase sonriente) reza uno [un cartel], para recordarle que, aquí en América, no tiene derecho a no sentirse feliz" (113). La dentífrica sonrisa de falsa felicidad que caracteriza a todo anuncio que se precie se erige, para Torres-García en la manifestación por antonomasia de la vulgaridad que subyace a la modernidad capitalista:

$\mathrm{Y}$, en casi todos esos anuncios (siempre), se ve pintado a un individuo satisfecho y sonriente - que fuma, satisfecho y sonriente- que se desayuna, satisfecho y sonriente. Satisfecho y sonriente, el niño exhibe la golosina azucarada, el candy, el producto maravilloso, el juguete. - Otro bebe, satisfecho y sonriente - otro muestra un traje elegante otro... mil, todos, satisfechos y sonrientes, muestran en qué consiste la felicidad y cómo puede obtenerse. - Yo, ahora, puedo afirmar esto: que New York, al menos en la mala pintura comercial, sonríe. Sonríe satisfecha, mostrando en qué consiste su felicidad y cómo puede obtenerse (81).

Por medio del machacante bombardeo publicitario, la publicidad impone un estado de ánimo a las masas. La felicidad es impuesta como la única reacción afectiva socialmente aceptable. La filosofía vital del materialismo norteamericano que denuncia Torres-García se reduce a una simple ecuación: se es feliz porque se consume y se consume para ser feliz.

17 Esta idea de la represión del talento artístico también se explora en la historia de Wood Gaylor, en la que se narra el caso de un artista norteamericano que acepta sin grandes tribulaciones trabajar de 9 a 5 como dibujante industrial y solo dedicar su tiempo libre a su vocación de "artista auténtico" (ver New York 155-57). 
Al señalar el estrecho vínculo entre los afectos y el consumo, TorresGarcía enfatiza la importancia que adquieren los significados connotativos en la efectividad discursiva de la publicidad. Como ya sugirió Roland Barthes, mediante los procesos de codificación de la publicidad, los productos anunciados adquieren un significado connotativo específico que los inserta en una dimensión simbólica que los eleva de meros objetos materiales a una "experiencia del espíritu" (96). La fuerza semántica de los significados connotativos movilizados por los anuncios es tal que, en última instancia, la publicidad no nos vende productos, sino los conceptos e ideas vinculados a estos. Como propugna Raymond Williams al analizar el enriquecimiento semántico producido por la publicidad, cuando se adquiere un producto, "uno no compra simplemente un objeto. Uno compra respeto social, distinción, salud, belleza, éxito, el poder de controlar su ambiente" (189). ${ }^{18}$

Este interés por el imperativo de la felicidad que domina el espacio público de la sociedad norteamericana lleva a Torre-García a confeccionar collages con recortes de anuncios publicitarios con ejemplos de sonrisas forzadas que ilustran el primer mandamiento de la industria publicitaria norteamericana: todo anuncio ha de incluir "un tipo, hombre, mujer, o niño, satisfecho y sonriente" (New York 113). Por si no fuese suficiente con la sonrisa eufórica, el eslogan del anuncio de la derecha vincula directamente la compra de un producto con la obtención de la satisfacción: "Happiness in Every Box" [La felicidad en cada caja]. La selección de este anuncio no es fortuita. Al sustituir metonímicamente el producto anunciado por un sentimiento, esta frase ilustra a la perfección las estrategias de significación por medio de las cuales la publicidad manipula afectivamente al comprador. En la frase "Happiness is Every Box" se expresa, además, con particular claridad, la insufrible vulgaridad del discurso publicitario. La noción de una felicidad comercializada, convertida en producto, y empaquetada convenientemente en cajas de cartón para el consumo de las masas, muestra cómo, en última instancia, la vulgaridad de la industria publicitaria estriba en su pueril mercantilización de sentimientos humanos banalizados hasta el absurdo.

A pesar de su atracción hacia la visualidad del anuncio, la refutación de la publicidad desarrollada por Torres-García en New York resulta demoledora. Al concebir la publicidad como una enorme industria discursiva de masas diseñada para canalizar hacia el banal ejercicio del consumo nuestras legítimas necesidades estéticas y espirituales, Torres-García denuncia los anuncios como un seductor ejercicio de falsificación, una mera fachada deslumbrante de colores, eslóganes y promesas que se deshace como un castillo en el aire una vez adquirido el producto. Desenmascarándola como

18 Esta capacidad del discurso publicitario para asociar connotativamente afectos e ideas a productos fue identificada ya en los años 1910 y 1920 por los teóricos de la publicidad como la principal técnica discursiva del anunciante y bautizada con el término de "sugestión indirecta". Sobre definiciones contemporáneas de la sugestión indirecta, véanse los tratados publicitarios de la época de Gérin 82, Bori y Gardó 52-57, y Scott 172-85. Sobre la dimensión connotativa de los anuncios, Iain MacRury defiende que "vender productos como si fuesen ideas" constituye "la razón de ser del proceso publicitario" (46). 
una fábrica de falsos sentimientos carente de autenticidad y carga espiritual, el pintor denuncia cómo el objetivo último de la industria publicitaria es la sistemática vulgarización, no solo de nuestros sentimientos y aspiraciones, sino de nuestra propia condición humana. Debido a su falta de autenticidad espiritual y afectiva, el valor artístico de la publicidad se desvirtúa hasta tal punto que esta es denunciada como el "pseudo-arte del anuncio" (127) - una vulgar imitación de las verdaderas aspiraciones y objetivos del arte legítimo que deshumaniza a las masas de compradores al promover pseudosentimientos y pseudoideales con el objetivo de vender más-.

Su enfático rechazo a la vulgaridad de la sociedad de masas cincelada por la publicidad, convence a Torres-García de la necesidad de construir activamente un espacio de independencia intelectual para el desarrollo de un proyecto verdaderamente vanguardista. Frente a la falsa sonrisa empaquetada del anuncio, Torres-García responde con una agria mueca de infelicidad. La insatisfacción que caracteriza el tono de la voz narrativa en New York constituye una estrategia discursiva orientada a la construcción performativa de un espacio de enunciación alternativo. En contraste con la "vacua y petulante invención de la vulgaridad" que toma forma en el discurso publicitario, Torres-García articula con la escritura de New York un espacio vanguardista de disensión - una esfera de libertad individual desde la cual oponerse a la vulgarización de las masas que alimenta la publicidad-.

Irónicamente, solo una vez confrontado cara a cara con la vulgaridad del "pseudoarte del anuncio", Torres-García encuentra una senda de radical experimentación estética que culmina hacia finales de los años 1920 con el desarrollo del estilo estético que le granjeará un lugar de excepción en la historia del arte latinoamericano -el Universalismo Constructivo-. Frente a la lógica estandarizante de la publicidad, el pintor se ve forzado a profundizar en su radical inconformismo vanguardista. Frente a la falsedad afectiva del anuncio, este necesita enarbolar con sus cuadros la necesidad de la autenticidad artística. A pesar de que en las páginas de New York, la estética vanguardista de Torres-García se convierte en el antídoto contra la vulgaridad publicitaria, irónicamente, el pintor uruguayo encuentra en su oposición a los perniciosos efectos del pseudoarte del anuncio, su mayor fuente de inspiración. 


\section{Imágenes}

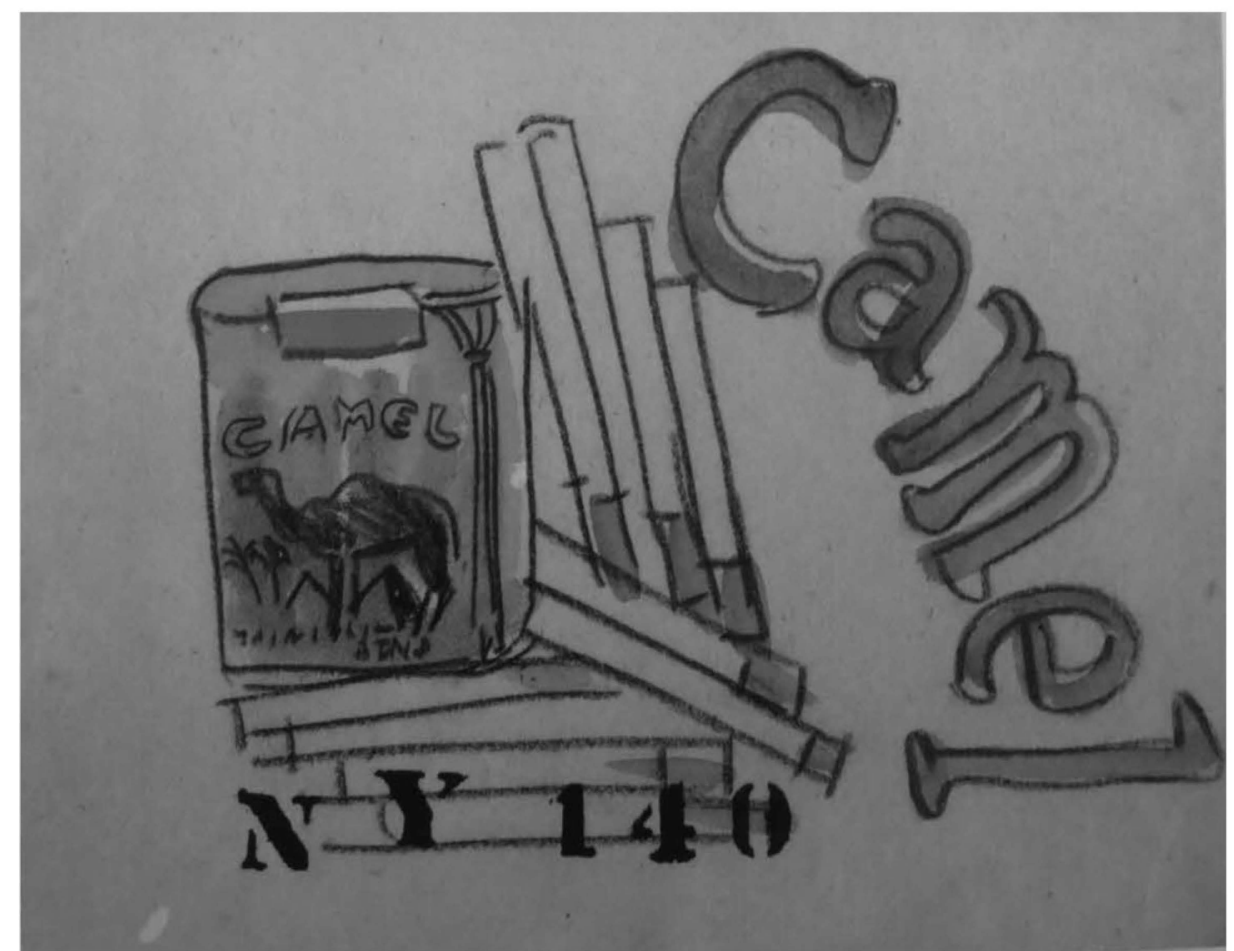

Imagen 1. Joaquín Torres-García, "Boceto de un anuncio de cigarrillos Camel". Álbum de acuarelas de New York (1920). S. pág.

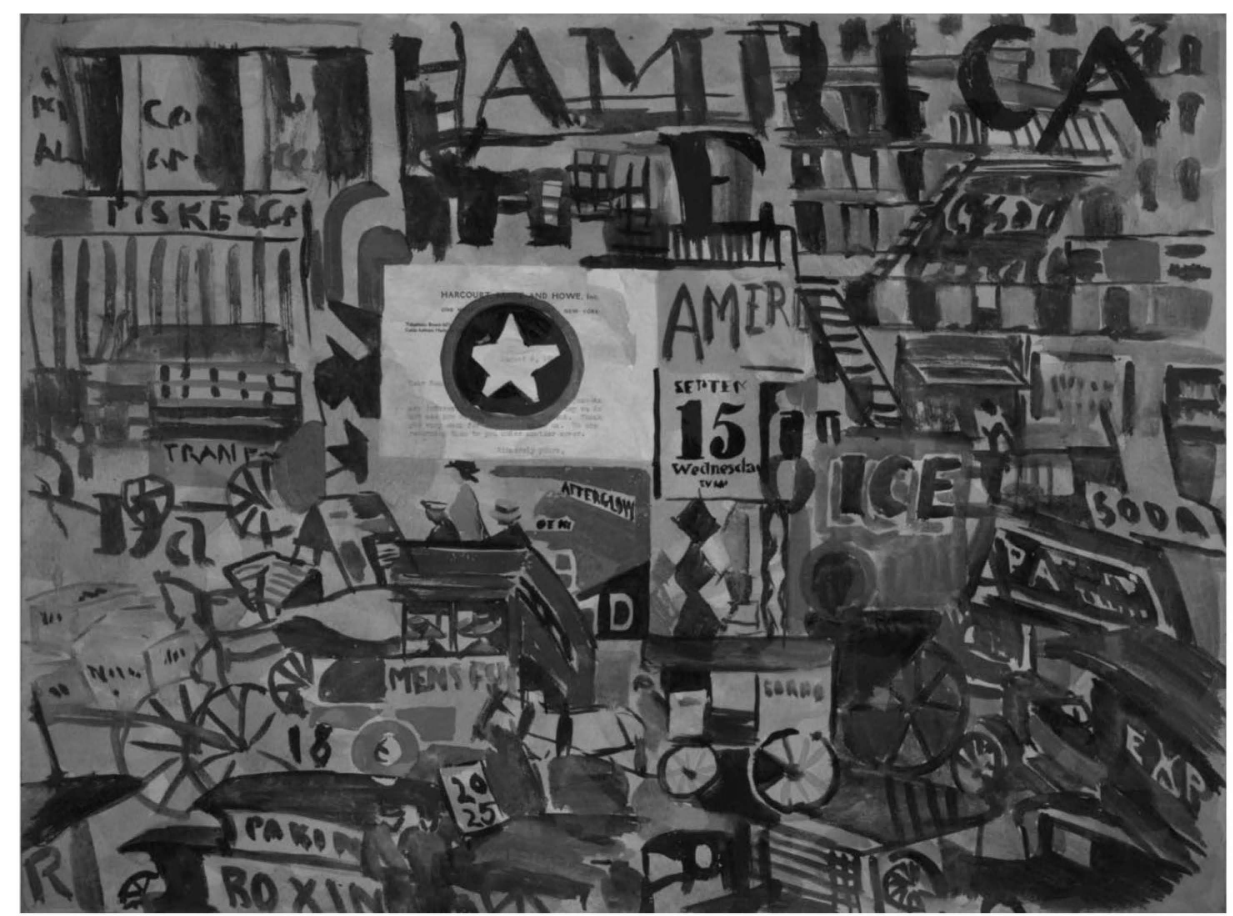

Imagen 2. Joaquín Torres-García, Escena callejera de Nueva York (1920). Yale Art Gallery. 


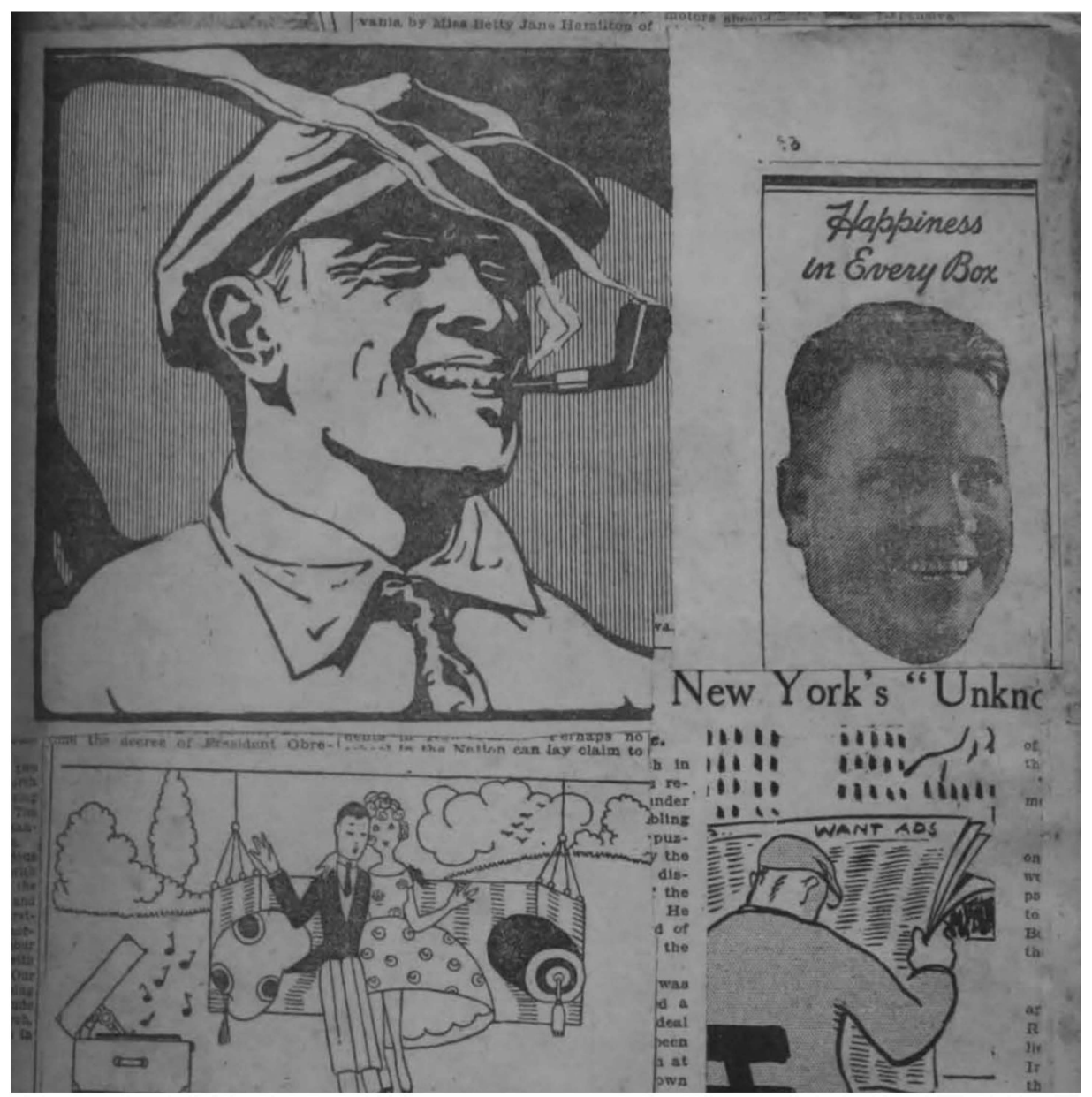

Imagen 3. Joaquín Torres-García, "Recortes publicitarios". Álbum de acuarelas de New York (1920). S. pág.

\section{Bibliografía}

Adorno, Theodor y Max Horkheimer. Dialektik der Aufklärung: Philosophische Fragmente. Frankfurt a. M.: Fischer, 1969.

Apollinaire, Guillaume. "Chroniques et paroles sur l'art: La peinture moderne". Fuvres complètes. 4 Vol. Ed. Michel Décaudin. París: Balland-Lecat, 1965-66. IV: 284.

Barthes, Roland. "Le message publicitaire: rêve et poésie". Les Cahiers de la Publicité 7 (1963): 91-96.

Baudrillard, Jean. "La publicité". Le système des signes. París: Gallimard, 1968. 229-74.

Bori, Rafael y José Gardó. Tratado completo de Publicidad y Propaganda. Barcelona: José Montesó, 1936.

Cendrars, Blaise. "Publicité = Poésie". Aujourd'hui. París: Grasset, 1931. 207-18.

Checa Godoy, Antonio. Historia de la publicidad. Oleiros: Netbiblos, 2007.

Dalí, Salvador, Lluís Montanyá y Sebastià Gasch. "Guia sinòptica. L'anunci comercial. Publicitat. Propaganda". Manifiestos, proclamas, panfletos y 
textos doctrinales (Las vanguardias artísticas en España: 1910-1931). Ed. Jaime Brihuega. Madrid: Cátedra, Madrid. 164-66.

Depero, Fortunato. "Il futurismo e l'arte pubblicitaria". Numero Unico Futurista Campari 1931. Edición facsímil. París: Jean-Michel Place, 1979. S. pag.

Drucker, Johanna. The Visible Word. Experimental Typography and Modern Art, 1909-1923. Chicago: Chicago UP, 1994.

Eco, Umberto. Apocalípticos e integrados. Trad. Andrés Boglar. Barcelona: Lumen, 2003.

Eguizábal Maza, Raúl. Historia de la publicidad. Madrid: Celeste, 1998.

Fló, Juan. "Torres García 1915-1920. Algunos enigmas". Trazos de New York 31-103.

"Introducción: Torres García - Nueva York". New York 7-50.

Gerbino, Giovanni. Poesia pubblicitaria. Dinamo Futurista 2 (1933). S. pag.

Gérin, Octave-Jacques. Publicité suggestive. Théorie et Technique. París: Dunot, 1911.

Jardí, Enric. Torres García. Barcelona: Polígrafa, 1973.

List Arzubide, Germán. "Paleta-chicles". Poemas estridentistas. México: El Tucán, 1998. 46-47.

"La novia extra. III". Poemas estridentistas 59-63.

Maples Arce, Manuel. "Prisma". Poemas radiográficos. Las semillas del tiempo: obra poética 1919-1980. México: FCE, 1981. 35-37.

McRury, Iain. Advertising. Londres: Routledge, 2009.

Méndez Dorich, Rafael. "Elegía de Jack Mike Black, Jack el virtuoso del saxo". Dibujos animados. Lima: Perú Actual, 1936. 150-56.

Rodó, José Enrique. Ariel. México: Porrúa, 2005.

Rokha, Pablo de. "Las tiendas". Los gemidos. Santiago de Chile: Cóndor, 1922. 226-27.

Scott, Walter D. The Psychology of Advertising in Theory and Practice. Boston: Small, Maynard \& Co., 1921.

Starch, Daniel. Advertising. Its Principles, Practice and Technique. Chicago: Scott, Foresman \& Co., 1914.

Torres, Cecilia de. "Torres García en Nueva York, 1920-22". Trazos de New York 17-32.

Torres-García, Joaquín. "Apunts sobre Nova York". La publicidad (30 de agosto, 1920). S. pag.

"Boceto de un anuncio de cigarrillos Camel". Álbum de acuarelas de New York. 1920. S. pag.

"Carta a José Enrique Rodó (Barcelona, 15 de marzo, 1916)". Museo Reina Sofía (Madrid). S. pag.

"Carta a Rafael Barradas (Nueva York, 29 de septiembre, 1920)". Joaquím Torres-Garcia i Rafael Barradas: un diàleg escrit, 1918-1928. Ed. Pilar García-Sedas. Barcelona: L'Abadia de Montserrat, 1994. 163-65. Diàlegs. Tarrasa: Mulleras, 1915.

El descubrimiento de sí mismo. Cartas a Julio, que tratan de cosas muy importantes para los artistas. Gerona: R. Masó, 1917.

Escena callejera de Nueva York (1920). Óleo y collage sobre cartón. Yale Art Gallery. Donación de la Colección Société Anonyme. 45.7 x $60.8 \mathrm{~cm}$.

Historia de mi vida. Montevideo: Asociación de Arte Constructivo, 1939.

La ciudad sin nombre. Montevideo: Asociación de Arte Constructivo, 1941. 
New York. Ed. e introd. Juan Fló. Montevideo: Fundación Torres García y HUM, 2007.

"New York". La publicidad (1920). S. pag.

" "New York. Los Artistas". La publicidad (1920). S. pag.

__ "Recortes publicitarios". Álbum de acuarelas de New York. 1920. Museo Torres-García. S. pag.

- Trazos de New York. Catálogo de Exposición. Curaduría a cargo de Jimena Perera y Alejandro Díaz. Montevideo: Museo Torres-García, 2011.

Williams, Raymond. "Advertising: the Magic System". Culture and Materialism. Londres: Verso, 2005. 170-95. 
